\title{
Vein of Galen malformation: What to do when vascular access is not feasible?
}

\author{
Marco Zenteno', Luis Rafael Moscote-Salazar ${ }^{2}$, \\ Jorge Santos-Franco ${ }^{3}$, Angel Lee ${ }^{4}$ \\ ${ }^{1}$ Instituto Nacional de Neurología y Neurocirugía "Manuel Velasco Suarez", Mexico \\ ${ }^{2}$ Universidad de Cartagena, Colombia \\ ${ }^{3}$ Centreo Medico IMSS La Raza, México \\ ${ }^{4}$ Hospital Ángeles del Pedregal, México
}

\begin{abstract}
Background: The vein of Galen aneurysmal malformation (GVAM) is a rare congenital vascular lesion, with high morbidity and mortality without treatment, endovascular management is the best alternative available today.

Aim: The purpose of this work is to report the case of a female patient with imaginological and angiographical diagnosis of GVAM, which was difficult for endovascular managent alone, due to this was decided an alternative endovascular direct access guided by stereotactic assistance.

Case report: We report the case of an infant with imaging and angiographic diagnosis of GVAM, with absence of the vein access through classical embolization could be done, complicating and making difficult for endovascular management alone, hence was decided an alternative endovascular direct access guided by stereotactic assistance, ensuring total embolization of the lesion with coils. The patient progressed satisfactorily.
\end{abstract}

Discussion: VGAM generally represents

only $1 \%$ or less of total cerebral vascular malformations, but in pediatrics may be as high as $30 \%$. The malformation is occupying the subarachnoid space of the velum interpositum and the quadrigeminal cistern. It is characterized by the presence of the vein embryonic precursor of the vein of Galen, and abnormal arterial shunts from arteries normally developed but extremely dilated. Mortality rate is high in these patients without treatment, developing hydrocephalus and cerebral complications related to the occupying mass that could drive to epilepsy, serious cognitive sequelae, intracerebral emorrhage and death within the possibilities. Heart failure is often a common complication. To our knowledge this is the first report of the use of stereotactic assistance in the endovascular therapeutic management of VGAM.

Conclusions: In cases where clasical venous access cannot be achieved as in the case we report, further technical assistance can be obtained with stereotactic guidance, making easier the procedure, remembering 
that without therapy, VGAM result in lifethreatening hydrocephalus and/or intracranial hemorrhage, rapidly driving to death.

Key words: vein of Galen aneurysmal malformation, endovascular management, stereotactic approach.

\section{Introduction}

The vein of Galen aneurysmal malformation (VGAM) is a rare cerebral vascular malformation firstly reported by Steinhel and cited by Dandy 1919, $(1,2)$ with a prevalence of less than $1 / 25,000$ deliveries. (3) VGAM are responsible for about $1 \%$ of all the vascular malformations and about $30 \%$ of the pediatric vascular malformations. $(4,5)$ They are characterized by the abnormal persistence of the Markowski's median porencephalic vein which, fueled by primitive embryonic meningeal arteries, becomes in the blood collector of this malformation. (6)

Two different subtypes of vein of VGAM can be distinguished, including the choroidal and mural types. Patients with the choroidal type have multiple arterial feeders draining on multiple different locations into the dilated median prosencephalic vein, and usually present with heart failure as newborns; the mural type is characterized by the confluence of all arterial feeders in one terminal fistula, which drains into the prosencephalic vein, and its presentation is later in infancy with macrocephaly or failure to thrive, which may be associated with mild cardiac failure or asymptomatic cardiomegaly. (7) Borthne and coworkers (8) used a different classification, see Table 1 . VGAM can be classified also as a "true" vein of Galen aneurysmal malformation or a "false". (9) A "true" VGAM involves a dilated median prosencephalic vein of Markowsky receiving drainage from multiple arteriovenous shunts. A "false" VGAM involves an arteriovenous malformation that drains into a tributary of the vein of Galen, resulting in its overload and dilatation.

The vasculature of VGAMs is very complex with choroidal arteries as the main feeding arteries. They form a fistula or multiple fistulae with the embryologic precursor of the Galenic vein, the median prosencephalic vein. This dilated embryogenetic vein drains through the socalled falcine sinus - which is in the embryogenesis the forerunner of the straight sinus - into the superior sagittal sinus. (5)

To note, high-flow arteriovenous malformation and fistula are commonly treated by using an endovascular approach with a variety of materials, such as detachable coils. We present the case of a female patient with imaginological and angiographical diagnosis of GVAM, which was difficult for endovascular managent alone, due to this was decided an alternative endovascular direct access guided by stereotactic assistance.

TABLE 1

\section{VGAM classification by Borthne et al (8)}

\begin{tabular}{|c|l|}
\hline Type & Characteristics \\
\hline I & $\begin{array}{l}\text { Direct fistulae to the pouch (median } \\
\text { prosencephalic vein). }\end{array}$ \\
\hline II & $\begin{array}{l}\text { Indirect arteriolovenous fistulae through } \\
\text { an intervening tangle of vessels (nidus) } \\
\text { between the arteries and the vein. }\end{array}$ \\
\hline III & $\begin{array}{l}\text { Combination of Types I and II: mixture } \\
\text { of direct arteriovenous and } \\
\text { arteriolovenous fistulae. }\end{array}$ \\
\hline
\end{tabular}


DOI: 10.2478/romneu-2014-0022

\section{Case report}

A child of 24 months presented with macrocania. Antenatal assessments revealed aneurysmal malformation of the vein of Galen. Endovascular management was decided by conventional technique but vascular access was not possible through the posterior cerebral arteries. The procedure was performed one week after direct approach to the aneurysm of the vein of Galen by stereotactic guidance (Leksell frame), is placed a stereotactic frame and direct approach was performed by parietal craniotomy, a complete embolization was performed in the aneurysmal malformation of the vein of Galen with coils. (Figure 1 A, B, $\mathrm{C}, \mathrm{D}, \mathrm{E})$ The child tolerate the procedure and was followed by an interval of six months.
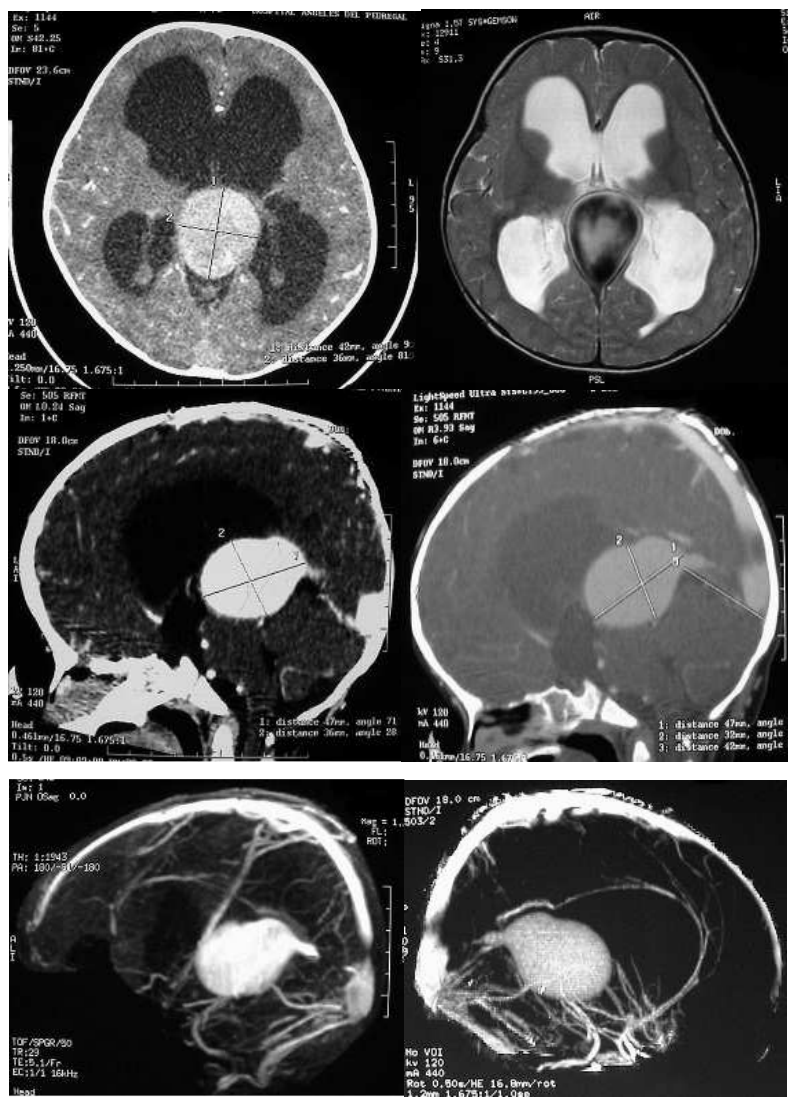

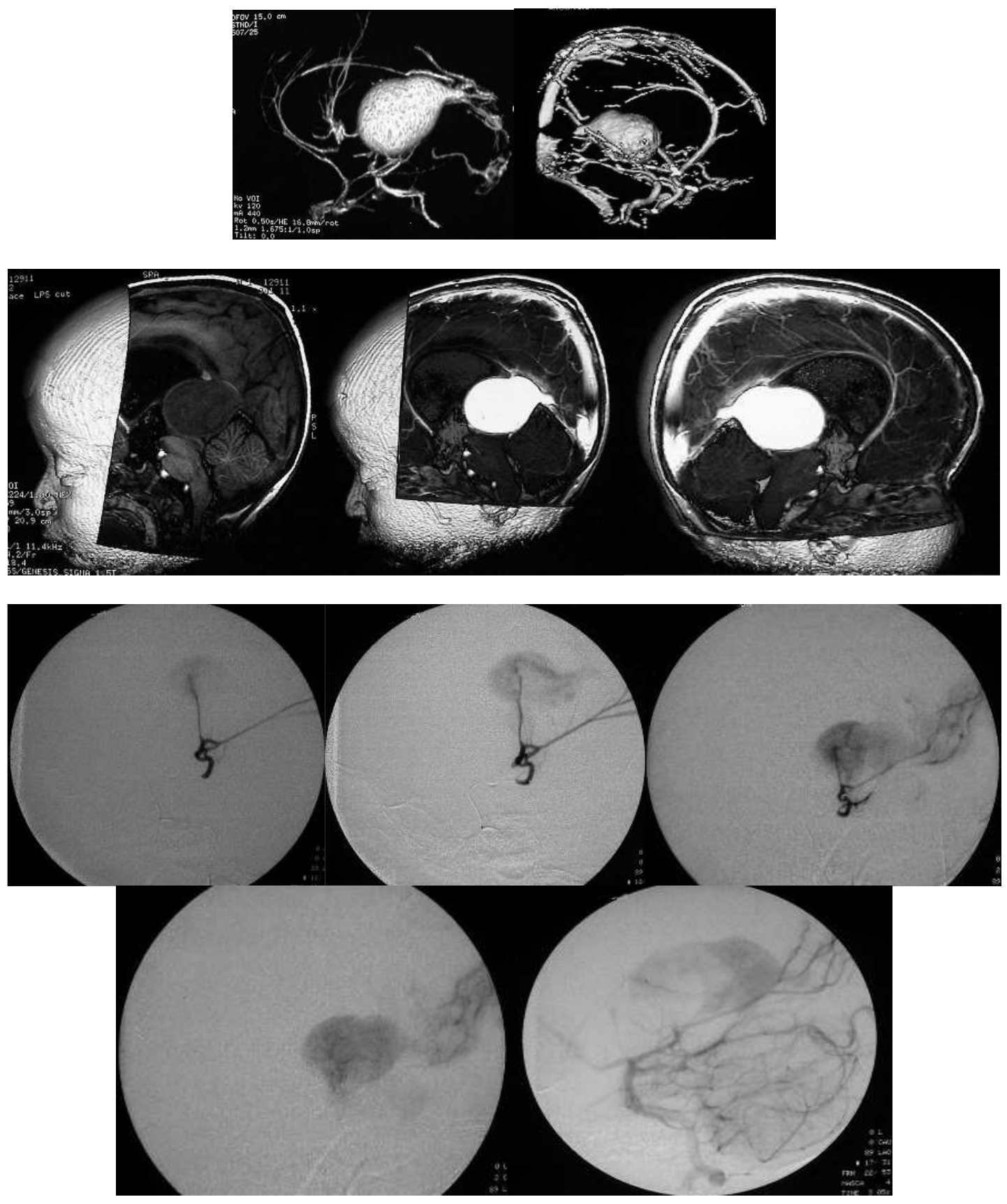

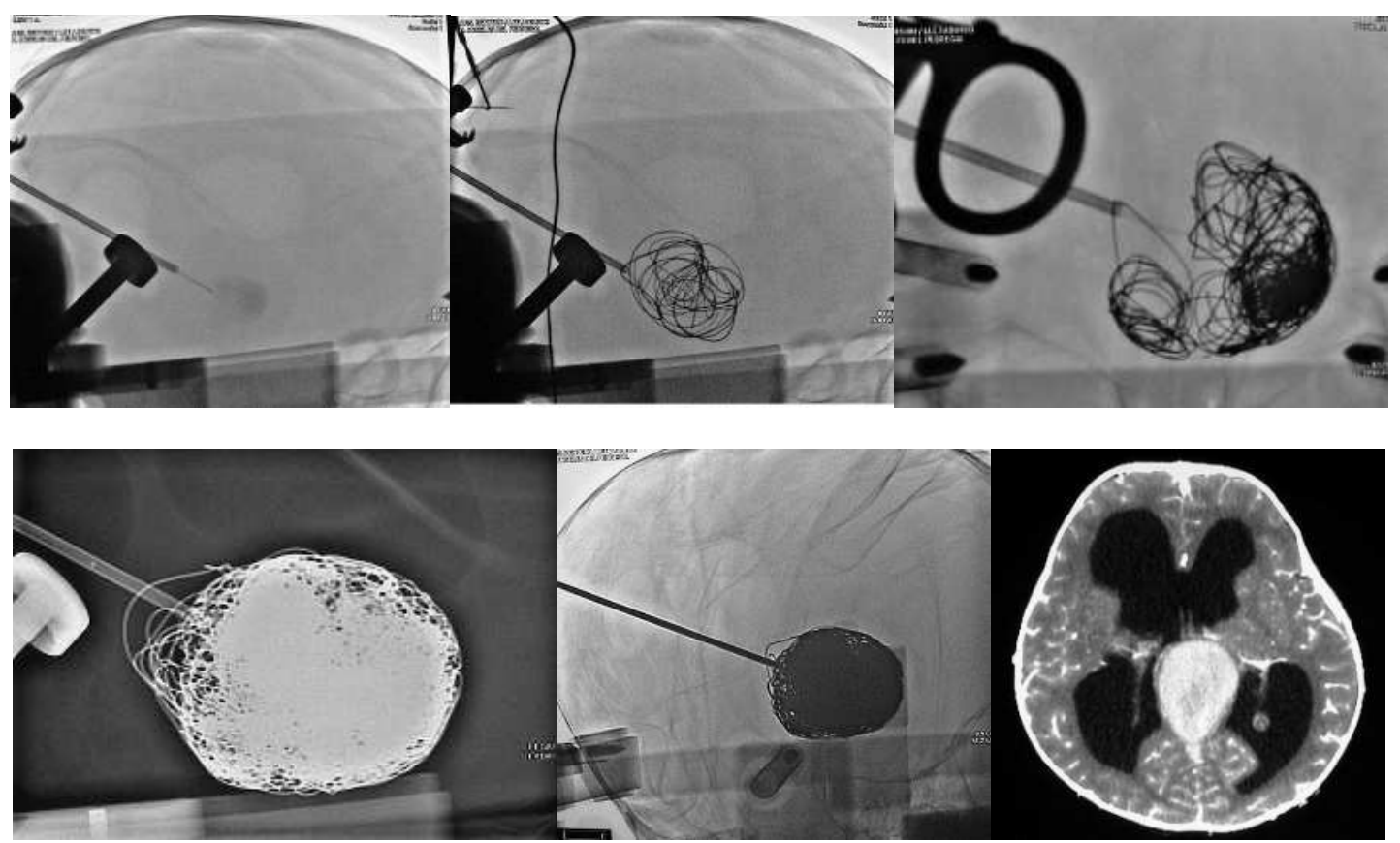

Figure 1

\section{Discussion}

In this report we present the case of a VGAM with absence of the vein access through classical embolization could be done, complicating and making difficult for endovascular management alone, hence was decided an alternative endovascular direct access guided by stereotactic assistance, ensuring total embolization of the lesion with coils. Patient evolution was remarkable. The malformation develops between the 6th and 11th weeks of gestation after the development of the circle of Willis. With the development of the basal ganglia, primitive internal cerebral veins form and fuse in the midline to form the vein of Galen and straight sinus, replacing the median prosencephalic vein as the main venous drainage of the choroid plexus. The caudal remnant of the median prosencephalic vein becomes part of the vein of Galen complex. Persistence of the median prosencephalic vein is a common finding in vein of Galen malformations. (10) The presence of a persistent falcine sinus (which normally regresses as the straight sinus develops) is also indicative of the arrested venous development that commonly occurs in the setting of a vein of Galen malformation. (10) Thus VGAM result from the development of an arteriovenous connection between the primitive choroidal vessels and the median prosencephalic vein of Markowski. The abnormal flow through the connection retards the normal involution of this embryonic vein and thus prevents the development of the vein of Galen. $(6,11)$ The most obvious feature is a midline intracranial vascular fistula with aneurysmal dilation of the vein of Galen. (12) 
Although diagnosed principally in the pediatric age group, may not be revealed until adulthood. Patients with VGAM have varying age-related clinical presentations. Clinically, vein of Galen aneurysmal dilation usually presents in childhood or young adulthood and shares clinical manifestations with other deep-seated arteriovenous malformations. Hydrocephalus as a presenting sign of VGAM usually occurs secondary to impaired cerebrospinal fluid (CSF) resorption due to venous hypertension. Cerebral venous circulation often is reversed and rerouted toward the cavernous sinus and ophthalmic veins (producing dilation of facial veins or epistaxis) or to the basisphenoid sinus and pterygoid veins. (7)

Management is a major therapeutic problem, currently, interventional neuroradiology is the therapeutical method of choice for VGAM, (14) which is influenced by VGAM's classification: the mural type can be treated via a transarterial or a transvenous approach, whereas, the choroidal type can be treated only via a transvenous approach, however, when classicao vein acces to the VGAM it is necessary to recur to alternative approaches or techniques, as we present here.

Despite neuroradiological intervention has been shown to control cardiac failure when present, there is a perception that neurological outcome in survivors is poor. (13) Lasjaunias et al., (15) reported that 216 patients were treated with endovascular embolization, from which, 23 died despite or because of the embolization (10.6\%). Twenty out of the 193 (10.4\%) surviving patients were severely retarded, 30 (15.6\%) were moderately retarded, and 143 (74\%) were neurologically normal on follow-up. Their data demonstrated that most treated children survive and undergo normal neurological development, as in our case, with the extra help of stereotactic guidance; the endovascular management was achieved without complications. To our knowledge this is the first report of the use of stereotactic assistance in the endovascular therapeutic management of VGAM. Complications regard the endovascular approache are scarce, Hyodo et al (16) reported the case of VGAM in which coil migration was observed during the endovascular procedure. Significant risk exists for either proximal or distal coil migration because of rapid flow. The cause of migration may be due to a size mismatch between the embolised coils and the caliber of the parent artery, probably due to redilatation of a constricted artery. Another possible mechanism is mechanical vasospasm due to catheter manipulation in the early stage of the endovascular procedure. (16)

\section{Conclusions}

Aggressive medical treatment of complications secondary to VGAM and urgent endovascular intervention has produced encouraging results, although early diagnosis remains a challenge. With more and more technological advances in the developments in the field of interventional neuroradiology and availability of better postprocedure intensive care, these once nontreatable conditions with a very high mortality rate are now potentially curable using interventional neuroradiological techniques with excellent clinical results, low complication rate and very low morbidity and mortality. In cases where clasical venous access cannot be achieved as in the case we 
DOI: 10.2478/romneu-2014-0022

report, further technical assistance can be obtained with stereotactic guidance, making easier the procedure, remembering that without therapy, VGAM result in lifethreatening hydrocephalus and/or intracranial hemorrhage, rapidly driving to death.

\section{References}

1. Dandy W. Experimental hydrocephalus. Ann Surg [Internet]. 1919 Aug [cited 2013 Oct 14];70(2):129-42. Available from:

http://www.pubmedcentral.nih.gov/articlerender.fcgi?ar tid $=1410318 \&$ tool $=$ pmcentrez\&rendertype $=$ abstract 2. Dandy W. Cerebrospinal fluid. Absorption. Chicago: American Medical Association; 1929. p. 2012.

3. Lasjaunias P, Hui F, Zerah M, Garcia-Monaco R, Malherbe V, Rodesch G, et al. Cerebral arteriovenous malformations in children. Management of 179 consecutive cases and review of the literature. Childs Nerv Syst [Internet]. 1995 Feb [cited 2013 Oct 14]; 11(2):66-79; discussion 79. Available from:

http://www.ncbi.nlm.nih.gov/pubmed/7758015

4. Casasco A, Lylyk P, Hodes JE, Kohan G, Aymard A, Merland JJ. Percutaneous transvenous catheterization and embolization of vein of galen aneurysms. Neurosurgery [Internet]. 1991 Feb [cited 2013 Oct 14];28(2):260-6. Available from:

http://www.ncbi.nlm.nih.gov/pubmed/1997895

5. Fellner F, Fellner C, Böhm-Jurkovic H, Blank M, Bautz W. MR diagnosis of vein of Galen aneurysmal malformations using virtual cisternoscopy. Comput. Med. Imaging Graph. [Internet]. 1999 Oct;23(5):293-7. Available from:

http://www.sciencedirect.com/science/article/pii/S08956 11199000270

6. Raybaud CA, Strother CM, Hald JK. Aneurysms of the vein of Galen: embryonic considerations and anatomical features relating to the pathogenesis of the malformation. Neuroradiology [Internet]. 1989 Jan [cited 2013 Oct 14];31(2):109-28. Available from: http://www.ncbi.nlm.nih.gov/pubmed/2664553

7. Abe T, Matsumoto K, Kiyota K, Tanaka H. Vein of Galen aneurysmal malformation in an adult: A case report. Surg. Neurol. [Internet]. 1996 Jan;45(1):39-42. Available from:

http://www.sciencedirect.com/science/article/pii/009030

\section{1}

8. Borthne A, Carteret M, Baraton J, Courtel J, Brunelle F. Vein of Galen vascular malformations in infants: clinical, radiological and therapeutic aspect. Eur Radiol [Internet]. 1997 Jan [cited 2013 Oct 14];7(8):1252-8. Available from: http://www.ncbi.nlm.nih.gov/pubmed/9377511

9. Lasjaunias P, Rodesch G, Pruvost P, Laroche FG, Landrieu P. Treatment of vein of Galen aneurysmal malformation. J Neurosurg [Internet]. 1989 May [cited 2013 Oct 14];70(5):746-50. Available from:

http://www.ncbi.nlm.nih.gov/pubmed/2709115

10. Davidson AS, Morgan MK. The embryologic basis for the anatomy of the cerebral vasculature related to arteriovenous malformations. J. Clin. Neurosci. [Internet]. 2011 Apr;18(4):464-9. Available from: http://www.sciencedirect.com/science/article/pii/S09675 8681000843X

11. Gupta VB, Choudhary H, Rastogi H, Singh VP. Intracranial arteriovenous malformation in an infantvein of Galen malformation. Apollo Med. [Internet]. 2011 Dec;8(4):307-9. Available from:

http://www.sciencedirect.com/science/article/pii/S09760 01611600148

12. Chen M-Y, Liu H-M, Weng W-C, Peng S-F, Wu E-T, Chiu S-N. Neonate With Severe Heart Failure Related to Vein of Galen Malformation. Pediatr. Neonatol. [Internet]. 2010 Aug;51(4):245-8. Available from: http://www.sciencedirect.com/science/article/pii/S18759 57210600472

13. Nelson M, Dickinson DF, Wilson N. Transtorcular coil embolisation of malformations of the vein of Galen-rapid resolution of heart failure in neonates. Int $\mathrm{J}$ Cardiol [Internet]. 1988 Mar [cited 2013 Oct 14];18(3):437-41. Available from:

http://www.ncbi.nlm.nih.gov/pubmed/3360528

14. Angelkova N, Kuturec M, Lekovska O, Duma F, Damjanovski G, Avramovska VS. P244 Vein of Galen malformation. Eur. J. Paediatr. Neurol. [Internet]. 2009 Sep;13, Supple(0):S97. Available from:

http://www.sciencedirect.com/science/article/pii/S10903 79809703022

15. Lasjaunias PL, Chng SM, Sachet M, Alvarez H, Rodesch G, Garcia-Monaco R. The management of vein of Galen aneurysmal malformations. Neurosurgery [Internet]. 2006 Nov [cited 2013 Oct 8];59(5 Suppl 3):S184-94; discussion S3-13. Available from: http://www.ncbi.nlm.nih.gov/pubmed/17053602 
16. Hyodo A, Yanaka K, Kato N, Nose T. Coil migration during endovascular treatment in a patient with Galenic arteriovenous malformation. J. Clin. Neurosci. [Internet]. 2002 Sep;9(5):584-5. Available from:
http://www.sciencedirect.com/science/article/pii/S09675 86802909744. 